\title{
Dietary manipulation in musculoskeletal conditions
}

In: Principles of Non-Pharmacological Management of Musculoskeletal Conditions. Best Practice and Research, Clinical Rheumatology, Issue 22.3.208. eds. Brooks \& Conaghan, Elsevier (in press)

*Professor Margaret Rayman BSc DPhil (Oxon) RPHNutr

Professor of Nutritional Medicine

Nutritional Sciences Division

Faculty of Health and Medical Sciences

University of Surrey

Guildford GU2 7XH

Tel: $+44(0) 1483686447$

Fax $+44(0) 1483300374$

E-mail: m.rayman@surrey.ac.uk

Dr Dorothy J. Pattison BSc, MSc, PhD (Registered Dietitian)

Honorary Research Fellow

ARC Epidemiology Unit,

Stopford Building,

The University of Manchester,

Oxford Road,

Manchester

M13 9PT

Tel: $+44(0) 1208841603$

E-mail: dorothy.pattison@manchester.ac.uk

*corresponding author

\begin{abstract}
Dietary advice and intervention do clearly have a place in rheumatology and allow patients to have some control over their own disease. Though there is no evidence of efficacy of 'fad' diets, $30-40 \%$ of rheumatoid patients can benefit from excluding foods individually identified during the reintroduction phase of an elimination diet. A proportion of patients that follow a vegetarian or Mediterranean-type diet will experience benefit. Patients that are either overweight or obese should participate in weight-loss programmes. Those with osteoarthritis need to concentrate on reducing fat mass, but maintaining muscle mass. Arthritic patients, other than those with gout, should increase their intake of oily fish and additionally supplement with fish oil for up to three months to see if they experience benefit. All arthritic patients, particularly those with inflammatory disease should be advised to ensure a good dietary intake of antioxidants, copper and zinc. Supplementation with selenium and vitamin D may be advisable.
\end{abstract}

Key words: rheumatoid arthritis, osteoarthritis, gout, ankylosing spondylitis, dietary exclusion, BMI, obesity, fish oil, micronutrients, antioxidants, vitamin D 
The use of diet to help control pain and symptoms of disease in musculoskeletal conditions is of great interest to patients because it is one way in which they can do something to help themselves. Though patients always ask about whether making alterations to their diet will help, rheumatologists have traditionally been sceptical, dismissing the idea that dietary manipulation might be effective. This is largely because of the paucity of evidence from well designed randomised studies. However, results from randomised controlled trials reflect aggregated findings from many subjects and may be missing possible benefits to individual patients and their specific needs. Doctors receive very little nutritional education and are therefore ill-equipped to advise on nutritional matters at an individual level. Even where they are open-minded, there is a shortage of dietitians to whom patients might be referred and even fewer have relevant experience. Though there is much self-help material available both in books and on-line for arthritis sufferers, little of it is well-informed and so they are at the mercy of marketing ploys that exploit their vulnerability. We aim to show here that dietary advice and intervention do clearly have a place in rheumatology so that patients can be provided with evidence-based recommendations on diet and supplements that may help to reduce the risk of disease progression and relieve symptoms in a risk-free manner.

Having critically examined some popular nutritional approaches, we will assess the evidence for the use of exclusion, elemental, vegetarian/vegan diets followed by a consideration of the impact of BMI, and the importance of fatty acids and micronutrients in arthritic conditions.

\section{Fad diets}

In practice, dietary modifications based on 'fad' diets may actually conflict with evidencebased dietary advice for arthritis and other clinical conditions, thus adding confusion and the potential for impairing nutritional status. Despite this, there is a huge amount of dietary advice aimed at people with arthritis. The vast majority of claims made by self-styled diets such as The Dong Diet, Sister Hills Diet and Norman F Childers Diet are unsubstantiated by science and based on individual experience, there being no evidence of objective overall clinical benefit [1]. However, data are consistent with certain types of dietary manipulation being beneficial for a subset of patients.

\section{Dietary manipulation}

Many patients have a poor response to, or are unwilling to tolerate the side effects of highly toxic drugs for long periods and often seek out other potential remedies such as dietary manipulation. Up to $75 \%$ of patients believe that food affects their condition [2]. For instance, there is a common belief that tomatoes and citrus fruits are 'acidic' and that consumption will exacerbate joint inflammation. In fact these foods have a $\mathrm{pH}$ raising (alkalinising) effect on the bloodstream, are rich in antioxidants such as vitamin $\mathrm{C}$, lycopene and $\beta$-cryptoxanthin and should be included in a healthy diet.

Self-imposed dietary exclusion is common in arthritic subjects and a dietary elimination programme designed to identify 'offending' foods is popular with patients. Specific dietary approaches such as vegan, vegetarian or Mediterranean diets or at the most extreme, an elemental diet have also been tried in rheumatoid arthritis (RA) [3]. Studies of this nature have not been carried out in osteoarthritis $(\mathrm{OA})$ patients therefore there is no evidence of efficacy in OA. 


\section{Exclusion Diet for RA}

There is evidence that patients can benefit from excluding foods individually identified during the reintroduction phase of an elimination diet. Darlington and colleagues [4] carried out a blinded, placebo-controlled study of food elimination in 53 rheumatoid patients. All subjects followed an exclusion phase for seven to ten days during which they ate a small range of rarely-eaten foods. Foods were then introduced, one by one, to see which ones caused symptoms. Any foods provoking reactions during the reintroduction phase were identified as culprit foods and avoided thereafter. Culprit foods varied from one individual to the next. Forty-four subjects finished the trial. Of these, $36 \%$ felt that after food exclusions they were much better and 39\% felt they were better. Objective measurements provided support for these findings: decreased pain and number of painful joints, reduced duration of morning stiffness, shorter time to walk 20 yards, better grip strength and improved ESR, haemoglobin, fibrinogen and platelet levels. Improvement on dietary therapy was found to be independent of weight loss [5]. Foods found most likely to cause intolerance by Darlington and Ramsey [5] are listed in Table 1. A more detailed explanation of the exclusion diet for RA is available elsewhere [3].

\section{The Elemental Diet in RA}

An elemental diet comprises mono/di-saccharides, amino acids, medium chain triglycerides and is supplemented with vitamins, minerals and trace elements. The diet is nutritionally complete and 'non antigenic'. It can be taken as an oral drink or administered by naso-enteric tube. The taste is not particularly pleasant although the flavours are becoming increasingly more palatable. Elemental diets have consistently been shown to induce improvements in subjective measures of RA symptoms in a sub-set of patients, with deterioration and return to baseline symptoms once the normal diet is re-introduced [6] [7] [8]. However, elemental diets are poorly tolerated though they may be used on a temporary basis as a diet of last resort.

\section{Fasting, vegetarian and vegan diets in RA}

Fasting appears to have an anti-inflammatory effect and confers pain relief during the fasting period [9] [10]. When eating is resumed, however, symptoms usually return. An alternative is a regime of fasting followed by a vegetarian diet. A systematic review of studies investigated the efficacy of this diet therapy [11]. Only four of 31 studies identified were independent controlled studies of fasting followed by a vegetarian diet for 3 months or more. The collective results showed statistically and clinically-significant, long-term benefits to patients.

\section{The 'Mediterranean' diet}

The 'Mediterranean diet' reflects the dietary patterns characteristic of several countries in the Mediterranean basin during the 1960s. Typically the diet comprises abundant plant foods (including fruits, vegetables, wholegrain cereals, beans, nuts and seeds), minimally-processed, seasonally-fresh and locally-grown foods, fish and poultry, olive oil as the main source of lipid with dairy products, red meat and wine in low to moderate amounts [3]. Thus, the diet is rich in long chain n-3 polyunsaturated fatty acids (PUFA) and oleic acid (n-9 monounsaturated), antioxidant nutrients and unrefined carbohydrates. 
Two recent studies of very different populations have reported clinical benefits in RA patients who adopted a 'Mediterranean-type' diet [12] [13]. In a randomised, controlled, parallel study, Swedish patients with RA $(n=26)$ who followed a modified Mediterranean (traditional Cretan) diet for three months reported a significant reduction in DAS28 and HAQ scores and in quality of life. No significant change was seen in controls following a regular diet $(n=25)$ [12]. Women with RA from socially deprived areas of Glasgow $(n=75)$ completed a 6-week educational programme with an emphasis on cooking and eating a 'Mediterranean type' diet. Controls $(n=55)$ were given general healthy eating information only. Women in the intervention group reported a healthier dietary intake and showed significant benefits compared with controls for patient global assessment at 6 months; pain score at 3 and 6 months, early morning stiffness at 6 months and HAQ at 3 months [13].

\section{Possible explanations for clinical improvements using diet therapy in RA}

A number of explanations have been put forward to explain the benefit of dietary therapy of which some of the more plausible are outlined below.

Elimination of foods to which the patient is allergic or intolerant: e.g. a gluten-free vegan diet regime in 66 patients with active RA reduced IgG antibody levels against gliadin with $41 \%$ of patients fulfilling the ACR2 20 improvement criteria compared to only $4 \%$ in the nonvegan diet controls [14].

Reduction in gastrointestinal permeability to bacterial and other antigens: Increased gut permeability, a result of the gut inflammation that exists in up to $67 \%$ of RA patients [15], possibly exacerbated by NSAID and DMARD treatment, can allow the passage of lumenal bacteria and polypeptides. These may be absorbed in quantities sufficient to produce immunological responses leading to overt expression of RA [5]. Highly spiced foods, cereal grains, lectins (from legumes/cereals) strong coffee or tea and alcohol can increase gut permeability. Avoiding these items could reduce GI permeability thus reducing disease symptoms.

Alteration in gut flora: The intestinal flora of RA patients differs from those of non-RA controls and patients appear to maintain a high frequency of small intestinal bacterial overgrowth [15]. Changes in faecal flora brought about by a vegetarian or vegan diet in a percentage of RA patients are associated with improvement in disease activity measures [16].

Exclusion of lectins: Lectins found in legumes and cereals may act as immunogens, allergens and gut irritants and may directly interact with digestive tract bacteria [17] [18]. Foods such as beans, wheat, peanuts, peas and lentils, contain lectins and indeed foods commonly associated with food allergy such as peanuts and wheat are particularly rich in lectins [5].

\section{Dietary therapy in gout}

For many patients with gout, lifelong hypouricaemic drug treatment is necessary, but for some patients, dietary and lifestyle modifications may suffice. A diet low in animal purines (offal, yeast, meat extract and shellfish) may still be prescribed for patients with gouty joint inflammation when not adequately controlled by drugs or if medication is unnecessary. Alcohol intake should be minimal with the exclusion of beers and fortified wines which increase serum uric acid. Additional non-alcoholic fluids up to two litres a day are advisable to avoid dehydration [19] [20]. 


\section{Dietary therapy in ankylosing spondylitis (AS)}

Nearly all AS patients possess the HLA-B27 gene. Elevated levels of specific antibodies against Klebsiella bacteria (found in normal bowel flora) have been reported in AS patients. It has been suggested that because Klebsiella possess two molecules which carry sequences resembling HLA-B27, microbes may be a trigger for the disease, and that reduction in these bowel flora could be beneficial in the treatment of AS. Bowel microbes depend on dietary starch for growth, thus a reduction in consumption of starchy foods has been proposed [21]. Existing evidence does not support the use of this dietary regime in routine practice [22].

\section{Recommendations}

- A fast followed by a vegan or lactovegetarian diet can have a long-term benefit on symptoms of RA for up to $45 \%$ of those who follow the regime.

- $30-40 \%$ of RA patients may benefit from an elimination diet followed by a reintroduction phase to identify 'culprit foods' that they must then avoid. Some can remain well, off all medication and controlled by diet alone, for periods of up to 12 years.

- A Mediterranean diet may benefit some people with RA.

- An elemental diet is unlikely to be an appropriate option except for those with food intolerance or who cannot tolerate drug treatment.

- Uninformed and unnecessary dietary restrictions will disturb normal diet and lifestyle patterns and increase the risk of nutritional deficiencies.

\section{BMI and Obesity \\ BMI and RA}

Around $15 \%$ of RA patients, probably those with the most severe disease are underweight [23]. Low BMI in RA patients may be a consequence of 'rheumatoid cachexia'. Rheumatoid cachexia is characterised by increased catabolism and resting energy expenditure, muscle wasting and anorexia and is associated with the production of the pro-inflammatory cytokines that play a key role in inflammation-mediated loss of appetite, weight loss and joint destruction [24].

By contrast, $40 \%$ of RA patients may be overweight [23], partly because of reduced physical activity. A high percentage of body fat, presenting as obesity, is a known and reversible component of CVD, the risk of which is already increased in people with RA. For a given level of body fat, the measured BMI of RA patients was significantly lower than that of controls [25]. Thus clinicians might do well to follow the suggestion of StavropoulosKalinoglou and colleagues [25] of adopting BMI cut-off points $2 \mathrm{~kg} / \mathrm{m}^{2}$ lower than normal in order to decide when to recommend dietary and lifestyle modification in RA patients to reduce the risk of cardiovascular co-morbidity.

\section{BMI and Gout}

Current guidelines for the management of gout recommend weight loss in those who are overweight [19]. A rapid reduction in weight is not advisable as this may trigger an attack of acute gout. Raised serum uric acid is associated with several conditions known collectively as the "metabolic syndrome" namely hyperlipidaemia, hypertension, obesity and insulin 
resistance [26] [27]. These co-morbidities should be addressed by dietary and lifestyle modification where possible.

\section{BMI and OA}

Obesity is a well-recognised risk factor for development of OA, particularly of the knee and hip [3]. High BMI is also associated with more severe disease in terms of the amount of pain experienced [28] and the need for joint replacement [29] [30].

Body weight, joint load and limb malalignment: Weight loss reduces knee-joint loads [31]: each pound of weight lost will result in a four-fold reduction in the load exerted on the knee per step during daily activities. Despite this consideration, the effect of body weight on disease progression has been less-consistently demonstrated than its effect on disease incidence [32]. While some longitudinal studies have shown that obese subjects have a higher rate of joint-space loss (assumed to be cartilage loss) compared with non-obese subjects, some studies of knee OA have shown no such association with disease progression [32]. Results recently published from the Rotterdam Study on 3585 people aged $\geq 55$ years selected on the basis of the availability of radiographs of baseline and follow-up, showed that a high BMI was associated with progression (loss of joint-space width) of knee OA (OR 3.2) but not of hip OA [33].

How do we explain this disparity in findings? One can intuitively appreciate that the knee joint might be more susceptible to loading than the hip joint as found in the Rotterdam Study, since it is known that for each $1 \mathrm{lb}$ increase in weight, the overall force across the knee in a single leg stance increases by 2-3 lb [34]. As for other explanations for disparate results, Felson and colleagues [35] cite problems with study design, loss to follow-up, and the inclusion of different types of patients. Furthermore, their results show that as far as OA of the knee is concerned, BMI-associated disease progression was related to the degree of limb malalignment, the effect being limited to knees in which there was moderate malalignment, presumably because of the combination of localised load from malalignment and the excess load from increased weight [32].

Inflammatory mediators from adipose tissue: Clearly the increased mechanical load on weight-bearing joints such as the hip, knee or feet resulting from obesity is likely to put extra strain on these joints. However, increase in adiposity is also associated with worsening symptoms in non-weight bearing joints such as the hand [35]. This association is probably explained by the fact that adipose tissue itself functions as an endocrine organ and is highly reactive metabolically, secreting a variety of factors (e.g. leptin, TNF- $\alpha$, cytokines) with inflammatory and other effects [36] [37]. Convincing evidence also exists that obesity is associated with the accumulation of macrophages which are responsible for almost all the adipose tissue TNF- $\alpha$ expression and the production of major amounts of other inflammatory markers [37]. Thus the chronic inflammation associated with high BMI may contribute to symptoms. The good news is that weight reduction is accompanied with an improvement in the inflammatory secretory pattern [37].

It is also important to note that systemic inflammation is associated most strongly with abdominal obesity, as visceral fat secretes IL- 6 directly into the portal vein and portal vein IL6 concentrations correlate directly with arterial CRP in obese subjects. Thus there is a direct link between visceral fat mass in particular and systemic inflammation [38]. 
A number of studies have indicated that loss of fat mass rather than weight-loss per-se is what is important. Results of a six-week weight control program in 22 OA patients showed that both decreasing body fat and increasing physical activity were more important than bodyweight loss or decreasing other indices of obesity in producing symptomatic relief of knee OA [39]. To reinforce this message, fat-free mass was found to be beneficially related to knee cartilage properties in 297 healthy adults while fat mass had a deleterious effect [40].

\section{Recommendations}

- Overweight or obese RA patients carry more fat mass for the same BMI and may therefore require earlier dietary and lifestyle modification to reduce CVD risk.

- Overweight patients with gout should aim for controlled weight loss.

- OA patients that are either overweight or obese should participate in weight-loss programmes aimed at reducing fat mass, particularly abdominal fat mass [40].

- OA patients will need simultaneous exercise programmes that include resistance exercise in order to maintain lean muscle mass.

\section{Polyunsaturated fatty acids \\ Metabolism of PUFAs and formation of eicosanoids}

PUFAs have a number of functions in the body, the most important of which in the context of arthritis is that they are precursors of important biological mediators [41]. The interaction between n-3 PUFAs and another group of essential fatty acids, the n-6 PUFAs, is central to the immunomodulatory function of n-3 PUFAs. Conversion of the parent n-3 PUFA, $\alpha-$ linolenic acid (ALA), to long-chain n-3 PUFAs eicosapentaenoic acid (EPA) and docosahexaenoic acid (DHA), and of the parent n-6 PUFA, linoleic acid (LA), to long chain n-6PUFAs, dihomo- $\gamma$-linolenic acid (DGLA) and arachidonic acid (AA), involves competition for the same enzyme systems (Figure 1[42]). AA is the precursor of the inflammatory series-2 prostaglandins $\left(\mathrm{PGE}_{2}\right)$ and series-4 leukotrienes $\left(\mathrm{LTB}_{4}\right)$, whereas EPA is metabolised to the less-inflammatory series-3 prostaglandins $\left(\mathrm{PGE}_{3}\right)$ and series-5 leukotrienes $\left(\mathrm{LTB}_{5}\right)$. Exogenous AA from consumption of meat and meat products leads to the formation of inflammatory eicosanoids, the amount produced correlating with inflammatory severity in RA [41]. By contrast, the EPA-derived prostaglandins attenuate these pro-inflammatory effects and are associated with anti-inflammatory responses [43].

\section{Beneficial effects of long-chain n-3 PUFAs, GLA and DGLA on inflammation} GLA, DGLA and long-chain n-3 PUFAs are able to decrease pro-inflammatory n-6 eicosanoid formation if the intake is sufficiently high compared to that of AA, and (to a lesser extent) LA. They do this by decreasing the amount of AA in membrane phospholipids and competitively inhibiting the production of AA-derived eicosanoids from COX and 5-LOX [44]. For example, when healthy subjects were supplemented with fish oil providing $2.1 \mathrm{~g}$ $\mathrm{EPA}+1.1 \mathrm{~g} \mathrm{DHA} / \mathrm{d}$ for 12 weeks, the amount of AA in plasma phospholipids and mononuclear cells decreased by $20 \%$ while that of EPA increased, altering the ratio of AA:EPA from 23:1 to 1.5:1 in plasma phospholipids and from 28:1 to $6: 1$ in mononuclear cells [45].

Other than altered eicosanoid production, long-chain n-3 PUFAs have other antiinflammatory effects: they decrease the expression of adhesion molecules, decrease leukocyte chemotaxis and both EPA and DHA produce novel anti-inflammatory lipids (resolvins and 
protectins) [46] [47]. By a combination of such mechanisms, EPA and DHA inhibit activation of the transcription factor, NF- $\mathrm{BB}$ and the release of inflammatory cytokines [47]. However, it has to be noted that not all human studies showed a reduction in inflammatory cytokines with dietary long-chain n-3 PUFAs perhaps because of polymorphisms in TNF genes that are known to affect the response to dietary fish oil [46].

\section{Interventions with plant oils in RA patients}

GLA is sourced from plant and seeds oils such as evening primrose oil, borage/starflower oil and blackcurrant seed oils [48] [49] [50]. Most studies that used between 0.36 and 2.8g/d GLA reported improvement in subjective measures including duration of morning stiffness and number of swollen and tender joints and also a reduction in use of non-steroidal antiinflammatory drugs (NSAIDs). In one study using $2.8 \mathrm{~g} / \mathrm{d}$ GLA, a statistically significant reduction in signs and symptoms of RA disease activity was reported [51].

The long-chain n-3 PUFAs, EPA and DHA, can be synthesised from $\alpha$-linolenic acid (ALA) found most commonly in green leafy vegetables, flaxseed/linseed and canola oils. However, the conversion of ALA to EPA and DHA is relatively inefficient and no good evidence exists to support the efficacy of sources of ALA in the management of RA [3] [52]. According to Calder [46], more than 10g/d ALA would be required for anti-inflammatory effects to be seen and even then, the effects will be much more modest than those exerted by long-chain n-3 PUFAs.

\section{Interventions with fish oil in RA patients}

Fish-oil interventions in RA have been favourably reviewed by a number of authors though none of these reviews was systematic in nature [42] [46] [53] [54] [55]. The doses used in fish-oil studies have mostly been from 1-7 g (EPA + DHA)/d, averaging about $3.5 \mathrm{~g} / \mathrm{d}$ [42] [46]. Dependent on the study, significant improvements have been seen in morning stiffness, tender joints, swollen joints, patient or physician assessment of disease activity, pain, grip strength, NSAID intake and in biochemical parameters, LTB4, IL1, CRP and ESR, with a consistent reduction in number of tender joints and duration of morning stiffness in RA patients treated for 12 weeks or more with a minimum daily dose of fish oil containing $3 \mathrm{~g}$ EPA/DHA [55].

Three meta-analyses have been carried out. The first by Fortin and colleagues showed that dietary fish-oil supplementation for three months significantly reduced tender joint count and morning stiffness compared with various control oils [56].

In a subsequent meta-analysis of randomised-controlled trials in RA, MacLean and colleagues [43] evaluated 21 studies chosen according to stringent inclusion criteria. Suggestive benefits from fish-oil treatment were found in four outcomes: patient assessed pain, swollen joint count, disease activity measured by ESR, and patient global assessment, though none reached statistical significance. However, of seven studies that assessed the effect of fish-oil on NSAID requirement among patients with RA, a significant reduction in requirement relative to placebo was demonstrated in three, a significant reduction relative to baseline requirements in three, and no difference in one [43].

More recently Goldberg and Katz [47] conducted a meta-analysis of 17 randomizedcontrolled trials, 15 of which were in RA, assessing the pain-relieving effects of EPA/DHA in 
patients with inflammatory joint pain. Statistically significant benefits were found for patientreported joint pain, duration of morning stiffness, number of painful and/or tender joints and NSAID consumption following supplementation with n-3 PUFAs for 3-4 months. Neither physician-assessed pain nor Ritchie articular index showed a significant effect [47].

Thus in summary, all three meta-analyses are in agreement that there are significant beneficial effects relating to number of tender joints, duration of morning stiffness, and requirement for NSAID treatment, though no significant effect was found on swollen joint count, ESR and patient's global assessment.

\section{Interventions with fish oil in RA patients with reduced n-6 PUFA intake}

Fish-oil treatment appears to be more efficacious with a low background AA intake [41] [46]. Volker and colleagues [57] gave RA patients $40 \mathrm{mg} / \mathrm{kg}$ body weight $/ \mathrm{d}(2-3 \mathrm{~g} / \mathrm{d})$ of fish-oil containing $60 \%$ of n-3 fatty acids for 15 weeks while ensuring that the patients consumed less than $10 \mathrm{~g} / \mathrm{d}$ of $\mathrm{n}-6$ PUFA. After 15 weeks there were significant improvements in the duration of morning stiffness, pain score, number of swollen joints, patients' and physicians' global assessment of disease activity and overall health assessment. Two further studies that restricted the intake of AA $(<90 \mathrm{mg} / \mathrm{d})$ or n-6 PUFA while supplementing with fish oil found a significantly reduced number of tender and swollen joints [58] and a reduction in CRP, IL-6 and TNF- $\alpha$ [59].

\section{Fish oil and $\mathrm{OA}$}

There are no published trials on the effect of n-3 fatty acids in OA, but there is a suggestion that long-chain n-3 PUFA supplementation might be beneficial for those with inflamed OA joints. In a small trial carried out in Wales, OA patients supplemented with cod liver oil showed reduced COX-2 expression, COX-2 protein levels and the levels of inflammatory eicosanoids were reduced in some cases (Prof John Harwood, personal communication, 2007). The mRNA expression of the aggrecanase ADAMTS-4, a matrix-degrading enzyme, was also reduced.

\section{Collateral benefits of increasing the intake of long-chain n-3 PUFAs}

Fish oils rich in n-3 PUFA have also been shown to be effective in secondary cardiovascular disease (CVD) prevention [60]. Indeed cardiovascular benefits have been noted at levels lower than those required for anti-inflammatory effects (i.e. at EPA/DHA intakes $<1 \mathrm{~g} / \mathrm{d}$ ) [61]. Given that people with RA are at an increased risk of cardiovascular morbidity increasing the intake of long-chain n-3 PUFAs may confer an additional benefit.

\section{Sources of fish oils}

Oily fish such as mackerel, pilchards, salmon, trout and herring are the richest source of EPA and DHA and make the largest contribution to their intake [62].

Studies show that an anti-inflammatory effect requires a minimum intake of $3 \mathrm{~g}$ EPA $+\mathrm{DHA} / \mathrm{d}$ [3]. To achieve this, the number of servings per week, for example, of salmon would be around 6-7 portions (average 150g serving). Six or more portions of fish per week is an unrealistic target and may be associated with excessive levels of intake of toxic contaminants such as dioxins, polychlorinated biphenyls (PCBs), and mercury [63], so other means must be 
used to increase tissue levels of long-chain n-3 PUFA. Fish oil supplements are clearly an effective route by which intake of long chain n-3 fatty acids can be increased, either as an adjunct to dietary intake [62] or as an optional strategy.

As a generalisation, marine oils come from the fish flesh and contain around 180mg EPA and $120 \mathrm{mg}$ DHA per $1 \mathrm{~g}$ capsule (i.e. a ratio of 3:2), whereas cod-liver oil comes from the fish liver and contains considerably lower quantities of EPA and DHA but also contains vitamins $A$ and D [64]. EPA-enriched capsules of fish oil containing a higher ratio of EPA to DHA (4:1) are also on sale but at a premium price. Vitamin $\mathrm{E}$ is generally also added to reduce the risk of lipid peroxidation of these highly unsaturated oils. High-strength oils are now available and therefore require fewer capsules per day to achieve an effective dose. Typically in a $1 \mathrm{~g}$ capsule, these high-strength oils contain around 310mg EPA and 210mg DHA. The dose required per day will depend upon the composition of the supplement and on the n-3 PUFA content of the remainder of the diet. If no oily fish is eaten, 40 high-strength capsules per week would provide the required dose of $21 \mathrm{~g}$ long-chain n-3 PUFA, i.e. approximately six capsules/day. Based on an intake of two portions of an oily fish per week giving an intake of $6.5 \mathrm{~g}$ EPA + DHA/week, an additional $14.5 \mathrm{~g}$ of long-chain PUFA would be needed which would be supplied by an intake of 28 high-strength capsules per week. Regulations applying to the production of fish oil supplements mean that fish oil is a cleaner source of long-chain n3 PUFA than oily fish itself [3].

Cod liver oil is a supplement that is commonly taken within this patient group. However, the $\mathrm{n}-3$ content is quite low (typically $170 \mathrm{mg}$ EPA + DHA) and a large amount would be required to produce straightforward anti-inflammatory effects. Furthermore, in a $1 \mathrm{~g}$ dose, 800-1,600 $\mathrm{g}$ vitamin A might be provided and it is thought that it may be unsafe to consume more than $1.5 \mathrm{mg}(1,500 \mu \mathrm{g} \equiv 5000 \mathrm{IU}) / \mathrm{d}$ of vitamin A on a long-term basis [65]. In particular, pregnant women should avoid using cod-liver oil as a means of controlling inflammation owing to the known teratogenic effects of vitamin A. However, $1 \mathrm{~g}$ of cod liver oil may contain 5-8 $\mu$ g vitamin D which may confer benefit (see below).

\section{Recommendations}

- RA patients should try to eat two portions of oily fish per week plus four high-strength capsules per day for a period of at least three months to see if they experience benefit.

- If there is a lack of benefit or a worsening in condition, the supplement should be stopped as fish oil may interact with TNF genotype to increase production of inflammatory mediators [3] [46].

- Efficacy may be improved by reducing the amount of n-6 PUFA in the background diet.

- The use of Canola/rapeseed and olive oil and olive-oil based spreads, in place of sunflower oil products would lead to a reduction in n-6 PUFA and might offer additional symptom relief particularly in the light of the recently-discovered anti-inflammatory activity of extra-virgin olive oil [66].

- OA patients might be advised to try a similar strategy for a three-month period to see if symptoms improve.

- Additional well designed studies of GLA supplementation are required to establish efficacy and dosage before recommendations can be made.

- Oily fish such as anchovies, herring, mackerel, sardines, sprats are not recommended for people with gout because they are a rich source of purines [19]. 


\section{Dietary antioxidants}

Antioxidant micronutrients such as vitamin $\mathrm{C}$, vitamin $\mathrm{E}$, and the carotenoids may have an important role in preventing and/or ameliorating oxidative stress caused by ROS/RNS in the inflammatory process.

The main antioxidants that have been studied in arthritic conditions are $\beta$-carotene, vitamin $C$ and vitamin $\mathrm{E}$. $\beta$-carotene is a powerful antioxidant that is part of the carotenoid family that contains the less-well known carotenoids $\beta$-cryptoxanthin, zeaxanthin, lycopene and lutein. Vitamin $\mathrm{E}$ is the most important lipophilic antioxidant, scavenging peroxyl radicals and terminating the free-radical lipid peroxidation chain reaction. It also inhibits arachidonic acid (AA) release from phospholipids and reduces eicosanoid formation resulting in a mild antiinflammatory effect [41]. Vitamin $\mathrm{C}$ has two main functions that are relevant to arthritis: it is the most important water-soluble antioxidant in intracellular and extracellular compartments but it is also needed for connective tissue synthesis and repair, being required for glycosaminoglycan synthesis and by the enzyme lysyl-hydroxylase for the hydroxylation of specific prolyl and lysyl residues in procollagen that stabilise the mature collagen fibril. Vitamin $C$ is used up in conditions of oxidative stress and so low vitamin $C$ status is common in those with rheumatic diseases [54].

Data from observational studies suggest an effect of antioxidant nutrients on disease progression both in inflammatory arthritis and in OA. Preliminary data suggest that a diet rich in antioxidants may dampen down the inflammatory response in early inflammatory joint disease [67].

McAlindon and colleagues [68] conducted a prospective observational study of the effect of dietary antioxidant nutrients (vitamin $\mathrm{C}, \mathrm{E}$ and $\beta$-carotene) on $\mathrm{OA}$ of the knee as part of the Framingham Osteoarthritis Cohort Study. A significant three-fold reduction in risk of OA progression, which related predominantly to a reduced risk of cartilage loss, was found for both the middle and the highest tertile of vitamin $\mathrm{C}$ intake. Those with high vitamin $\mathrm{C}$ intake also had a significantly-reduced risk of developing knee pain. A significant though lessconsistent reduction in risk of OA progression was also seen for $\beta$-carotene.

\section{Trials of antioxidant supplements of in arthritis}

A recently-published systematic review of randomized clinical trials (RCTs) of antioxidant vitamins $\mathrm{A}, \mathrm{C}, \mathrm{E}$ and selenium (Se) in the treatment of arthritis identified 20 unique RCTs meeting the inclusion criteria: 11 in inflammatory arthritis and 9 in OA [69]. Excluding Se which is dealt with separately below, there were five trials of vitamin $\mathrm{E}$ in inflammatory arthritis and seven in OA. One RCT suggested superiority of vitamin E over placebo and three RCTs suggested equivalence between vitamin $\mathrm{E}$ and diclofenac in the treatment of inflammatory arthritis: vitamin E supplementation appeared to reduce pain [70] [71] [72]. In OA, four RCTs compared vitamin E with placebo. Two shorter-term studies were positive and two longer-term studies were negative. Two further RCTs suggest equivalence between vitamin $\mathrm{E}$ and diclofenac in the treatment of OA. There was an isolated positive result for vitamin $\mathrm{C}$ in $\mathrm{OA}$.

The authors report that as the studies included are generally of poor quality, there is no robust evidence that antioxidant vitamins are effective in any type of arthritis. They recommend that 
the positive effect of vitamin $\mathrm{E}$ on pain in some shorter-term studies of OA and inflammatory arthritis needs to be tested in RCTs using more methodologically robust protocols [69].

\section{Recommendation}

- Ensure an adequate daily intake of dietary antioxidants (see Table 2) [73]).

- A modest vitamin $\mathrm{C}$ supplement might be advised for those with OA if dietary intake is low.

- RA patients might try a vitamin E supplement (up to $400 \mathrm{mg} / \mathrm{d}$ ) for up to three months to see if pain is diminished.

- There is no scientific evidence to support the practice of mega-dosing with nutritional supplements. High doses of individual nutrients can be harmful.

\section{Selenium}

\section{Functions of selenium relevant to $\mathrm{RA}$ and $\mathrm{OA}$}

The potential of selenium to affect RA can be understood from the following Se-associated effects:

- Antioxidant selenoenzymes, such as glutathione peroxidise (GPx) reduce lipid hydroperoxides (or $\mathrm{H}_{2} \mathrm{O}_{2}$ ) to harmless alcohols $\left(\right.$ or $\mathrm{H}_{2} \mathrm{O}$ ) thus reducing oxidative stress [74].

- GPxs can modulate the production of biologically active eicosanoids by the COX and LOX pathways [74].

- Se down-regulates the expression of inflammatory genes [75].

- Selenoprotein P scavenges the powerful inflammatory agent peroxynitrite which is produced in inflamed joints [54] [76].

- Selenium may reduce the ability of matrix metalloproteinases (MMPs) to cause cartilage breakdown by inducing tissue inhibitors of MMPs (TIMPs) [77].

- Selenium may inhibit neovascularisation which is central to the development and perpetuation of rheumatoid synovitis [78] [79].

\section{Selenium status in OA and RA patients}

Low concentrations of selenium have been measured in plasma or serum of RA patients from different parts of the world when compared to controls, reflecting the observed association between selenium concentration, clinical indices of disease activity and biochemical parameters of inflammation [3].

Only one study, described as a preliminary account, has evaluated selenium status in OA patients [79]. Selenium status in 940 newly enrolled participants was found to be lower in those with radiographically determined knee OA, bilateral knee OA and severe knee OA ( $p \leq$ 0.05) than in those with normal X-rays. For those in the highest compared to the lowest tertile of toenail selenium, the odds $(95 \% \mathrm{CI})$ of knee OA were $0.62(0.37,1.02)$, for bilateral knee OA $0.79(0.31,0.97)$, and severe knee OA $0.56(0.34,0.94)$, suggesting that selenium may be a potentially modifiable risk factor for OA.

\section{Intervention studies with selenium}


Of seven randomised trials of selenium supplementation in RA [3], three reported significant improvements in measurable parameters of disease activity. In the first, a dose of $200 \mu \mathrm{g} / \mathrm{d}$ showed significant beneficial changes in the selenium group for pain at three months and number of joints involved at three and six months [80]. The second study used the same dose but both Se and placebo groups also received fish oil fatty acids at $30 \mathrm{mg} / \mathrm{kg}$ body weight [81]. At the end of three months, fewer tender or swollen joints, morning stiffness and a reduction in steroid and NSAID use were reported. The third trial using a higher dose (600 $\mu \mathrm{g}$ selenium as selenium-enriched yeast) found no significant effect at four months but a significant improvement at eight months in articular pain index, grip strength and morning stiffness [82]. However, a recent systematic review of trials of antioxidant vitamins and selenium in arthritis has pointed out that the trials are methodologically weak, in particular presenting no between-group statistical comparisons from which proper assessment of the treatment effect can be made [69]. Thus satisfactory randomised controlled trial evidence for a benefit of selenium in RA is currently lacking.

\section{Recommendations for selenium intake}

- Recommended daily intakes (average $53 \mu \mathrm{g} / \mathrm{d}$ for women and $60 \mu \mathrm{g} / \mathrm{d}$ for men) are not currently achieved in the majority of European countries together with parts of China [83].

- RA patients appear to have lower selenium status than healthy individuals and a greater requirement for antioxidants owing to the oxidative stress and inflammation associated with their condition [3].

- As selenium is found in good concentrations only in a small number of foods [84] - Brazil nuts, organ meats and fish (Table 2) - supplementation should be considered [41].

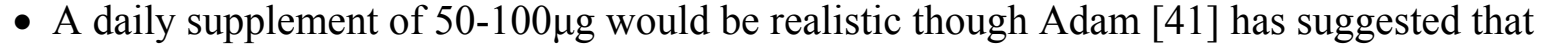
an intake of $300 \mu \mathrm{g} / \mathrm{d}$ is necessary to improve the status of RA patients.

- Supplements containing 100 or $200 \mu \mathrm{g}$ are readily available and have been associated with health benefits in many studies [84].

\section{Copper, zinc and RA and OA}

\section{Functions of copper and zinc relevant to $R A$ and $O A$}

Zinc and copper are key components of important metalloenzymes. Dietary deficiency of either copper or zinc will markedly decrease tissue concentration of the cytosolic antioxidant enzyme, superoxide dismutase (CuZnSOD) resulting in peroxidative damage to the joint [85].

Zinc metalloenzymes such as MMPs are involved in the degradation of connective tissue and cartilage breakdown [86]. Copper on the other hand has a key role in building the extracellular matrix by cross-linking proteins such as collagen and elastin to give them structural integrity [87]. Copper and zinc act in concert to maintain connective tissue. However, on the negative side, copper is required for angiogenesis and its chelation suppresses RA [88] and adjuvant-induced arthritis [89].

\section{Copper and zinc status in OA and RA patients}

A five-day dietary survey of 48 RA patients in New Zealand suggested that only $10 \%$ achieved the recommended dietary intake of zinc [90]. Low serum zinc has certainly been reported in RA patients [90] [91], but it may be more likely to be a consequence of inflammation and disease activity than of reduced dietary intake [91]. In inflammatory 
rheumatic diseases, the operation of the acute phase response causes redistribution of the element within body compartments, such that there is a decrease in plasma zinc and an increase in plasma copper [93].

However, CuZnSOD activity has been found to be significantly lower in RA patients [94] [95]. Such data suggest that there might be some benefit in increasing the activity of this enzyme that can remove superoxide.

\section{Intervention studies with copper and zinc}

Studies have looked at the effects of zinc supplementation on clinical outcomes of RA. Highdose zinc has been shown to improve symptoms in one study [96] but not in others [91] [41]. Naveh and colleagues carried out a zinc supplementation study in RA patients: the results suggest zinc malabsorption and therefore zinc deficiency in the RA patients [92].

Malabsorption may be the reason why no benefits were seen after zinc supplementation [91].

Early uncontrolled work on copper supplementation in RA reported beneficial effects [82]. A later study by DiSilvestro and colleagues [94] administered $2 \mathrm{mg}$ of copper/d for four weeks to 23 RA subjects and 47 matched controls. Before supplementation, erythrocyte CuZnSODactivity was significantly lower in RA patients than in controls but increased in 18 out of 23 RA patients following supplementation, suggesting "marginal copper status in RA patients" [94].

Intra-articular injections of CuZnSOD have been shown to reduce joint inflammation and provide benefit in both RA and OA suggesting the need for adequate intakes of both of these micronutrients [82] [54].

\section{Zinc and copper status}

The need for concerted synthesis and degradation of connective tissue in addition to the role of both zinc and copper in SOD, suggest the need for adequate intakes of both of these micronutrients. It is therefore of some concern that in the latest UK National Diet and Nutrition Survey of people aged 65 and over, the intake of copper fell below the RNI in $82 \%$ of free-living participants and in $90 \%$ of those in institutions, while the corresponding figures for zinc were $62 \%$ and $54 \%$ [97]. Though intake figures were better in the survey of younger adults, even then, median copper intake was below the RNI in women ( $82 \%$ of RNI) [98].

\section{Recommendations for intake of copper and zinc in RA and OA}

- Dietary intake of copper and zinc should reach the RDA/RNI level (copper 0.9-1.2mg/d; zinc $9.5-11 \mathrm{mg} / \mathrm{d}$ men, $7-8 \mathrm{mg} / \mathrm{d}$ women).

- Good food sources of zinc and copper are shown in Table 2.

- Given the potential of copper to catalyse redox reactions producing the hydroxyl radical, supplementation with copper above RDA/RNI levels is to be avoided while doses of zinc more than twice the RDA/RNI may impair copper absorption [99].

\section{Iron in RA and OA}

\section{Functions of iron relevant to $R A$ and $O A$}

In active RA, the inflamed synovium is subject to recurrent traumatic microbleeding and iron is deposited as ferritin in the synovium [100]. The ischemia-reperfusion cycles that occur 
within the inflamed joint lead to the production of superoxide $\left(\mathrm{O}_{2}{ }^{-*}\right)$ which can mobilise iron from ferritin. Free iron (or haem) has the capacity to form the highly toxic and destructive hydroxyl radical from $\mathrm{O}_{2}{ }^{--}$and hydrogen peroxide by the Fenton reaction causing tissue damage within the joint [100]. Thus a high iron status is contraindicated in OA and RA patients.

\section{Iron status in arthritic patients}

Anaemia is a common co-morbidity in individuals with RA, mild anaemia being present in between $33 \%$ and $60 \%$ of patients [101]. This may be iron-deficiency anaemia resulting from gastrointestinal bleeding provoked by the use of NSAIDs, but around $60 \%$ of the time in RA patients, it is anaemia of chronic disease which is associated with the severity of the condition [102] [103]. In the latter case, there will be low levels of plasma iron despite packed iron stores [41]. Haematological tests (see [3]) should be used to distinguish those RA patients whose anaemia might benefit from simple iron therapy from those with anaemia of chronic disease (or folic acid/vitamin $\mathrm{B}_{12}$ deficiencies) who require different treatment.

\section{Recommendations for iron intake}

- Ensure that dietary intake of iron is adequate.

- As high iron status may be detrimental, worsening inflammation, iron supplements should not be given unless there is evidence of a true deficiency.

\section{Vitamin D}

Vitamin D may come from the diet (vitamin $\mathrm{D}_{2}$ in foods of plant origin, vitamin $\mathrm{D}_{3}$ in foods of animal origin) or from the action of sunlight (UVB) on the skin (vitamin $\mathrm{D}_{3}$ ). It is converted into 25 -hydroxyvitamin $\mathrm{D}[25(\mathrm{OH}) \mathrm{D}]$ in the liver and to the active D-hormone, 1,25-dihydroxyvitamin $\mathrm{D}\left[1,25(\mathrm{OH})_{2} \mathrm{D}\right]$ by further hydroxylation in the kidney, though several other tissues also possess the enzyme, $1 \alpha$-hydroxylase, allowing local production of $1,25(\mathrm{OH})_{2} \mathrm{D}$ (Figure 2, [104]).

While the role of vitamin D in calcium homeostasis and maintenance of skeletal health is well recognised, it is less well known that vitamin D or its metabolites have important effects on muscle function and the immune system [105]. Receptors for $1,25(\mathrm{OH})_{2} \mathrm{D}(\mathrm{VDR})$ are present in more than 30 different tissues [104] while VDR polymorphisms have been found to be associated with the occurrence [106], time of onset [107], severity [108] and accelerated bone loss [109] in RA and with risk of early knee OA [110] and presence of osteophytes [111]. Evidence for the importance of vitamin D in RA and OA is assessed below.

\section{Vitamin D in RA}

If vitamin D levels are inadequate, the immune system tends towards the development of selfreactive Th1 cells and autoimmunity [112]. In support of this assertion, a significant inverse association was found between vitamin D intake and RA risk in a prospective study of 30,000 women (the Iowa Women's Health study) [113].

Partly as a result of inhibition of renal $1-\alpha$-hydroxylase by TNF- $\alpha$, people with inflammatory diseases exhibit markedly reduced circulating concentrations of D-hormone [105] which have been shown to correlate with the extent of RA disease activity. In 96 RA patients grouped 
according to disease activity, serum concentration of $1,25(\mathrm{OH})_{2} \mathrm{D}$ correlated negatively $(\mathrm{P}<$ 0.001 ) with disease activity both in patients with and without glucocorticoid treatment [114].

A high-quality, recently-published study backs up these findings. In 206 consecutive patients with newly diagnosed inflammatory polyarthritis (IP) enrolled in the Norfolk Arthritis Register, an inverse relationship was found between baseline $25(\mathrm{OH}) \mathrm{D}$ and tender joint count, DAS28 and HAQ score [115]. At 1 year, there was a significant inverse association between baseline concentrations of both $25(\mathrm{OH}) \mathrm{D}$ and $1,25(\mathrm{OH})_{2} \mathrm{D}$ and the HAQ score and a significant inverse association between $25(\mathrm{OH}) \mathrm{D}$ and tender joint count. The strength of this study is that patients were evaluated early after disease onset, had not been treated with steroids and were either not treated with DMARDs or had taken them for less than 6 weeks.

Though supplementation with $1,25(\mathrm{OH})_{2} \mathrm{D}$ in autoimmune animal models of RA markedly suppressed disease activity [116], human trials of vitamin D or its metabolites in RA have not shown such a clear outcome. Of five small intervention studies [104], three showed a significant improvement in disease activity or pain. Those that showed benefit used high doses of vitamin D $(2500 \mu \mathrm{g} / \mathrm{d}=100,000 \mathrm{IU} / \mathrm{d})$ [117] or $50 \mu \mathrm{g} / \mathrm{d} 25(\mathrm{OH}) \mathrm{D}[118]$ or $2 \mu \mathrm{g} / \mathrm{d}$ of the synthetic $1,25(\mathrm{OH})_{2} \mathrm{D}$ precursor, alfacalcidol $\left[1 \alpha(\mathrm{OH}) \mathrm{D}_{3}\right][119]$. The relatively disappointing findings of these small intervention studies may well be a consequence of the inhibition of renal 1- $\alpha$-hydroxylase by TNF- $\alpha$, resulting in poor conversion to the active hormone, $1,25(\mathrm{OH})_{2} \mathrm{D}$ [105]. Thus there may be a case for the treatment of RA patients with a synthetic vitamin-D hormone such as alfacalcidol in cases where vitamin $\mathrm{D}$ cannot be metabolised effectively.

In fact the argument for increasing vitamin $\mathrm{D}$ intake in RA patients can be made independently on other grounds: on the basis of its bone-sparing effects; its pleiotropic effects on other autoimmune diseases, muscle function, cancer risk, cardiovascular disease and diabetes; and the wide prevalence of vitamin D deficiency not only in RA patients but in the general population as described below [104] [120] [121].

\section{Vitamin D and OA}

Vitamin D appears to be able to stimulate the synthesis of proteoglycan by articular chondrocytes [122]. The effect of vitamin D was investigated within the Framingham OA Cohort study [123]. In the 556 participants that had complete assessments, a three- to fourfold significantly-increased risk of progression of radiographically-determined OA, was seen in the middle and low tertiles of vitamin D intake and serum concentration [122].

Furthermore, the 'Study of Osteoporotic Fractures Research Group' showed that high serum concentration of vitamin D protected against both incident and progressive hip OA [124].

However more recent results from two longitudinal cohort studies, the Framingham Offspring cohort (715 subjects) and the Boston Osteoarthritis of the Knee Study (BOKS) (277 subjects) [125] found no association of baseline $25(\mathrm{OH}) \mathrm{D}$ concentration with radiographic worsening of joint space narrowing nor any relationship with cartilage loss.

Though the evidence is contradictory for OA, the wide prevalence of vitamin D deficiency and the broad range of important roles played by vitamin D suggest that even OA patients should be encouraged to optimise their vitamin D status as outlined below [104] [120] [121]. 


\section{Vitamin $D$ and osteoporosis in RA and OA}

Patients with RA are at an elevated risk of developing osteoporosis [126]. A significant positive association has been observed between serum $25(\mathrm{OH}) \mathrm{D}$ and bone density in $\mathrm{OA}$ patients [127]. Vitamin D inadequacy is particularly common in patients with osteoporosis [121]. While vitamin D supplementation has been suggested as having the capacity to enhance bone mineral density in OA patients, plain vitamin D is not as effective as the synthetic vitamin D hormone, alfacalcidol, which improves bone and muscle metabolism and clinical symptoms in patients with RA [105].

\section{Vitamin D status}

As the main source of vitamin D is from the action of sunlight on the skin, Vitamin D deficiency is widespread in people living at latitudes where the sun's rays (UV-B) do not have enough power to penetrate the skin to trigger vitamin $\mathrm{D}$ synthesis and in those who spend little time outdoors [121] [104]. UV-B radiation is negligible from October to April at latitude $52^{0} \mathrm{~N}$ and from November to February at $42^{0} \mathrm{~N}$ [104]. Furthermore, vitamin D synthesis is markedly reduced in elderly skin, in dark skin, when enveloping clothing is worn or when sun-tan cream is applied. Vitamin D status is measured by the serum concentration of $25(\mathrm{OH}) \mathrm{D}$. Several studies have reported that $40-100 \%$ of European and US elderly men and women living in the community are deficient in vitamin $\mathrm{D}$, as defined by a level of $25(\mathrm{OH}) \mathrm{D}<50 \mathrm{nmol} / \mathrm{L}(\equiv 20 \mathrm{ng} / \mathrm{ml})[121]$. A concentration of $52-72 \mathrm{nmol} / \mathrm{L}$ can be considered to indicate relative insufficiency of vitamin $\mathrm{D}$ whereas a level $\geq 75 \mathrm{nmol} / \mathrm{L}$ indicates sufficiency [121]. A recent study of 45-year old British adults showed a high prevalence of hypovitaminosis D during the winter and spring, when $25(\mathrm{OH}) \mathrm{D}$ concentrations $<25,<40$, and $<75 \mathrm{nmol} / \mathrm{L}$ were found in $15.5 \%, 46.6 \%$, and $87.1 \%$ of participants, respectively [120].

Vitamin D status is lower in vegetarians than in omnivores and fish eaters and is particularly low in vegans [3]. As vitamin D is fat-soluble, it tends to go to ground in fatty tissue, removing it from the circulation and creating a state of deficiency or relative deficiency in overweight or obese people [121].

\section{Sources of vitamin $D$}

Food sources of vitamin D are few and many people do not eat them (Table 2). Oily fish such as salmon, mackerel and sardines are by far the best sources, supplying from 360$1000 \mathrm{IU}(8-25 \mu \mathrm{g})$ per portion [3]. Dried shiitake mushrooms (1600 IU/100 g) are a very rich source though an unusual dietary component in the West. One egg yolk supplies approximately $20 \mathrm{IU}$. In the US, milk, which is fortified, makes the biggest contribution to vitamin D intake while orange juice is also frequently fortified [3]. Though margarines are fortified in many countries, they seem to make little contribution to vitamin D intake [120]. Cod liver oil can supply 400-100 IU/teaspoon but its high vitamin A content makes it unsuitable for consumption in pregnancy [121] [3]. Vitamin D supplements may provide cholecalciferol (vitamin $\mathrm{D}_{3}$ ) or ergocalciferol (vitamin $\mathrm{D}_{2}$ ), though the latter is only $20-40 \%$ as effective in maintaining $25(\mathrm{OH}) \mathrm{D}$ levels [128].

\section{Recommendations}

- Patients with RA (and even those with OA) who do not have adequate sun exposure should be recommended to ensure that they have frequent meals of oily fish, a good vitamin D source. 
- RA patients who do not eat oily fish should supplement with $1000-2000 \mathrm{IU}(25-50 \mu \mathrm{g}) / \mathrm{d}$ as cholecalciferol (vitamin $\mathrm{D}_{3}$ ). (Cod-liver oil is an alternative source and contains 5-8 $\mu \mathrm{g}$ vitamin $\mathrm{D}_{3} / \mathrm{g}$.)

- Vegetarians or vegans will prefer to supplement with vitamin $\mathrm{D}_{2}$ (ergocalciferol) but will need to increase the dose three-fold.

- If in doubt as to whether vitamin $\mathrm{D}$ status is adequate, have serum $25(\mathrm{OH}) \mathrm{D}$ measured. The value should reach $75 \mathrm{nmol} / \mathrm{L}$ [121].

- Though patients with failing kidneys or kidney disease may additionally require a synthetic D-hormone analogue such as alfacalcidol, this will not replace the need for vitamin $\mathrm{D}$ as a source of $25(\mathrm{OH}) \mathrm{D}$ for local conversion in tissues [121].

\section{Summary}

Dietary manipulation may benefit a significant subset of RA patients whether it be by adopting a vegan, lactovegetarian or Mediterranean diet or by avoiding culprit foods identified with the help of an appropriate health professional. Overweight/obese RA patients require dietary and lifestyle modification to reduce CVD risk while those with gout need controlled weight loss. Weight-loss programmes for overweight or obese OA patients must reduce fat mass without losing lean muscle. Patients with inflammatory joint disease (other than gout) may benefit from increasing their intake of n-3 PUFA from oily fish and/or fish-oil supplements. Reducing the background intake of $n-6$ PUFA by replacing sunflower/safflower/corn/soybean oils by Canola/rapeseed and olive oil products should improve efficacy. A good daily intake of dietary antioxidants is important to counteract the oxidative stress associated with inflammatory joint disease and there is some evidence that pain in RA patients may be improved by a vitamin E supplement. OA progression has been shown to be lower in OA patients with good vitamin C intake. RA patients appear to have lower selenium status than healthy individuals. Selenium has recognised anti-inflammatory effects but European selenium status is low. Though adequate copper and zinc status is important for the maintenance of connective tissue, high iron status may be detrimental. Vitamin D is an important nutrient for bone health and musculoskeletal function. Populations in northern Europe who do not eat much oily fish will require vitamin D supplementation. Important co-morbidities may also respond to dietary modification: the risk of CVD, metabolic syndrome, obesity and underweight may be reduced.

\section{Practice points}

- A fast followed by a vegan or lactovegetarian diet can have a long-term benefit on symptoms of RA for up to $45 \%$ of those who follow the regime while a Mediterranean diet may benefit a sub-group of RA patients.

- A sub-group of RA patients may benefit from a professionally-supervised elimination diet followed by a reintroduction phase to identify 'culprit foods' that they must then avoid: however uninformed and unnecessary dietary restrictions will disturb normal diet and lifestyle patterns and increase the risk of nutritional deficiencies.

- Overweight or obese RA patients carry more fat mass for the same BMI and may therefore require earlier dietary and lifestyle modification to reduce CVD risk.

- Overweight patients with gout should aim for controlled weight loss.

- Overweight or obese OA patients should participate in weight-loss programmes aimed at reducing fat mass and in simultaneous exercise programmes to avoid loss of lean muscle. 
- RA patients should try to eat two portions of oily fish per week plus four high-strength fish-oil capsules per day for a period of at least three months to see if they experience benefit while OA patients with joint inflammation could also be advised to increase their intake of oily fish or try treatment with fish oil/cod liver oil for a three-month period to see if symptoms improve. Efficacy may be improved by reducing the amount of n-6 PUFA in the background diet.

- Patients should ensure a good daily intake of dietary antioxidants. OA patients may need a modest vitamin $\mathrm{C}$ supplement if dietary intake is low. RA patients might try a vitamin $\mathrm{E}$ supplement (up to $400 \mathrm{mg} / \mathrm{d}$ ) for up to three months to see if pain is diminished.

- RA patients appear to have lower selenium status than healthy individuals and a greater requirement for antioxidants owing to the oxidative stress and inflammation associated with their condition. As selenium status is low in Europe and few foods are good selenium sources, supplementation up to $200 \mu \mathrm{g} / \mathrm{d}$ should be considered.

- Dietary intake of copper and zinc should reach the RDA/RNI level (see

Recommendations). Iron supplements should not be given unless there is evidence of a true deficiency.

- Patients with RA (and even those with OA) who do not have adequate sun exposure or do not eat oily fish will require a dietary vitamin D supplement (see Recommendations). If in doubt as to whether vitamin $\mathrm{D}$ status is adequate, have serum $25(\mathrm{OH}) \mathrm{D}$ measured.

- There is no scientific evidence to support the practice of mega-dosing with nutritional supplements. High doses of individual nutrients can be harmful.

\section{Research agenda}

- Nutritional interventions in patients with less-severe/early disease appear to have had more success. Such studies are needed to investigate the influence of diet on disease course.

- Further investigation of the efficacy of vitamin E supplementation is warranted, particularly of $\gamma$-tocopherol as it (and its major metabolite) is a much stronger antiinflammatory agent than $\alpha$-tocopherol.

- High quality trials of selenium and vitamin D supplementation are needed in RA and OA with pain and functionalityas the primary outcome measures.

- Detailed investigations of the influence of background diet on patients' response to medication are warranted.

- Future dietary interventions should include genetic testing where relevant polymorphisms may exist or at the very least, samples should be laid down for DNA isolation and later genotyping wherever possible. 


\section{References}

1. Panush R, Carter R, Katz P et al. Diet therapy for rheumatoid arthritis. Arthritis Rheum 1983; 26: 462-471.

2. Garrett SL, Kennedy LG \& Calin A. Patients' perceptions of disease modulation by diet in inflammatory (rheumatoid arthritis/ankylosing spondylitis) and degenerative joint disease. Br J Rheumatol 1993; 32: 24.

3. Rayman MP \& Callaghan A. Nutrition and Arthritis. Oxford: Blackwell Publishing, 2006.

4. Darlington LG, Ramsey NW \& Mansfield JR. Placebo-controlled, blind study of dietary manipulation therapy in rheumatoid arthritis. Lancet 1986; 1: 236-238.

5. Darlington LG \& Ramsey NW. Review of dietary therapy for rheumatoid arthritis. Br J Rheumatol 1993; 32: 507-514.

6. Haugen MA, Kjeldsen-Kragh J \& Førre Ø. A pilot study of the effect of an elemental diet in the management of rheumatoid arthritis. Clin Exp Rheumatol 1994; 12: 275-279.

7. Kavanagh R, Workman E, Nash $P$ et al. The effects of elemental diet and subsequent food reintroduction on rheumatoid arthritis. Br J Rheumatol 1995; 34: 270-273.

8. Podas T, Nightingale JMD, Oldham R et al. Is rheumatoid arthritis a disease that starts in the intestine? A pilot study comparing an elemental diet with oral prednisolone. Postgrad Med J 2007; 83: 128-131.

9. Udén A, Trang L, Venizelos N \& Palmblad J. Neutrophil functions and clinical performance after total fasting in patients with rheumatoid arthritis. Ann Rheum Dis 1983; 42: 45-51.

10. Haugen M, Fraser D \& Førre, Ø. Diet therapy for the patient with rheumatoid arthritis? Rheumatology (Oxford) 1999; 38: 1039-1044.

11. Müller H, de Toledo FW \& Resch KL. Fasting followed by vegetarian diet in patients with rheumatoid arthritis: a systematic review. Scan J Rheumatol 2001; 30: 1-10.

12. Sköldstam L, Hagfors L \& Johansson G. An experimental study of a Mediterranean diet intervention for patients with rheumatoid arthritis. Ann Rheum Dis 2003; 62: 208-214.

13. McKellar G, Morrison E, McEntegart A et al. A pilot study of a Mediterranean-type diet intervention in female patients with rheumatoid arthritis living in areas of social deprivation in Glasgow. Ann Rheum Dis 2007; 66: 1239-1243.

14. Hafström I, Ringertz B, Spångberg A et al. A vegan diet free of gluten improves the signs and symptoms of rheumatoid arthritis: the effects on arthritis correlate with a reduction in antibodies to food antigens. Rheumatology (Oxford) 2001; 40: 1175-1179.

15. Cordain L, Toohey L, Smith MJ \& Hickey MS. Modulation of immune function by dietary lectins in rheumatoid arthritis. Br J Nutr 2000; 83: 207-217.

16. Peltonen R, Nenonen M, Helve $T$ et al. Faecal microbial flora and disease activity in rheumatoid arthritis during a vegan diet. Br J Rheumatol 1997; 36: 64-68.

17. Pusztai A. Dietary lectins are metabolic signals for the gut and modulate immune and hormone functions. Eur J Clin Nutr 1993; 47: 691-699.

18. Darlington LG. Joints and arthritic disease. In Brostoff J \& Challacombe SJ (eds) Food Allergy and Intolerance. $2^{\text {nd }}$ edn, pp 747-760. London: WB Saunders, 2002.

19. Zhang W, Doherty M, Bardin T et al. EULAR evidence based recommendations for gout. Part II: Management. Report of a task force of the EULAR Standing Committee For International Clinical Studies Including Therapeutics (ESCISIT) Ann Rheum Dis 2006; 65: 1312-1324.

20. Jordan KM, Cameron JS, Snaith M et al on behalf of the British Society for Rheumatology and British Health Professionals in Rheumatology Standards, Guidelines and Audit Working Group (SGAWG). British Society for Rheumatology and British 
Health Professionals in Rheumatology Guideline for the Management of Gout. Rheumatology (Oxford) 2007; doi: 10.1093/rheumatology/kem056a

21. Ebringer A \& Wilson C. The use of a low starch diet in the treatment of patients suffering from ankylosing spondylitis. Clin Rheumatol 1996; 15(suppl 1): 62-66.

22. Zochling J, van der Heijde D, Dougados M et al. Current evidence for the management of ankylosing spondylitis: a systematic literature review for the ASAS/EULAR management recommendations in ankylosing spondylitis. Ann Rheum Dis 2006; 65: 423-432.

23. Morgan SL, Anderson AM, Hood SM et al. Nutrient intake patterns, body mass index, and vitamin levels in patients with rheumatoid arthritis. Arthritis Care Res 1997; 10: 917.

24. Kaufmann J, Kielstein V, Kilian S et al. Relation between body mass index and radiological progression in patients with rheumatoid arthritis. J Rheumatol 2003; 30: $2350-2355$.

25. Stavropoulos-Kalinoglou A, Metsiod GS, Koutedakis Y et al. Redefining overweight and obesity in rheumatoid arthritis patients. Ann Rheum Dis 2007; 66: 1316-1321.

26. Dessein PH, Shipton EA, Stanwix AE et al. Beneficial effects of weight loss associated with moderate calorie/carbohydrate restriction, and increased proportional intake of protein and unsaturated fat on serum urate and lipoprotein levels in gout: a pilot study. Ann Rheum Dis 2000; 59: 539-543.

27. Fam AG. Gout, diet and the insulin resistance syndrome. J Rheumatol 2002; 29: 13501355.

28. Marks R. Obesity profiles with knee osteoarthritis: correlation with pain, disability, disease progression. Obesity (Silver Spring) 2007; 15: 1867-1874.

29. Cooper C, Inskip H, Croft P et al. Individual risk factors for hip osteoarthritis: obesity, hip injury, and physical activity. Am J Epidemiol 1998; 147: 516-522.

30. Liu B, Balkwill A, Banks E et al. Relationship of height, weight and body mass index to the risk of hip and knee replacements in middle-aged women. Rheumatology (Oxford) 2007; 46: 861-867.

31. Messier SP, Gutekunst DJ, Davis C \& DeVita P. Weight loss reduces knee-joint loads in overweight and obese older adults with knee osteoarthritis. Arthritis Rheum 2005; 52: 2026-2032.

32. Felson DT, Goggins J, Niu J et al. The effect of body weight on progression of knee osteoarthritis is dependent on alignment. Arthritis Rheum 2004; 50: 3904-3909.

33. Reijman M, Pols HA, Bergink AP et al. Body mass index associated with onset and progression of osteoarthritis of the knee but not of the hip: the Rotterdam Study. Ann Rheum Dis 2007; 66: 158-162.

34. Felson DT, Lawrence RC, Dieppe PA et al. Osteoarthritis: new insights. Part 1: the disease and its risk factors. Ann Intern Med 2000; 133: 635-46.

35. Creamer P \& Hochberg MC. Osteoarthritis. Lancet 1997; 350: 503-508.

36. Hauner H \& Hochberg Z. Endocrinology of adipose tissue. Horm Metab Res 2002; 34: 605-606.

37. Hauner H. Secretory factors from human adipose tissue and their functional role. Proc Nutr Soc 2005; 64: 163-169.

38. Fontana L, Eagon JC, Trujillo ME et al. Visceral fat adipokine secretion is associated with systemic inflammation in obese humans. Diabetes 2007; 56: 1010-1013.

39. Toda Y, Toda T, Takemura S et al. Change in body fat, but not body weight or metabolic correlates of obesity, is related to symptomatic relief of obese patients with knee osteoarthritis after a weight control program. J Rheumatol 1998; 25: 2181-2186. 
40. Wang Y, Wluka AE, English DR et al. Body composition and knee cartilage properties in healthy, community-based adults. Ann Rheum Dis 2007; 66: 1244-1248.

41. Adam O. Anti-inflammatory diet in rheumatic diseases. Eur J Clin Nutr 1995; 49: 703 717.

42. Calder PC \& Zurier RB. Polyunsaturated fatty acids and rheumatoid arthritis. Curr Op Clin Nutr Met Care 2001; 4: 115-121.

43. Maclean $\mathrm{CH}$, Mojica WA, Morton SC et al. Effects of omega-3 fatty acids on lipids and glycemic control in Type II diabetes and the metabolic syndrome and on inflammatory bowel disease, rheumatoid arthritis, renal disease, systemic lupus erythematosus, and osteoporosis. Summary, Evidence Report/Technology Assessment No. 89. (prepared by the Southern California/RAND Evidence-based Practice Center, Los Angeles, CA.) AHRQ Publication No. 04-E012, Rockville, MD: Agency for Healthcare Research and Quality, March 2004.

44. James MJ, Proudmann SM \& Cleland LG. Dietary n-3 fats as adjunctive therapy in a prototypic inflammatory disease: issues and obstacles for use in rheumatoid arthritis. Prostaglandins Leukot Essent Fatty Acids 2003; 68: 399-405.

45. Yaqoob P, Pala HS, Cortina-Borja M et al. Encapsulated fish oil enriched in alphatocopherol alters plasma phospholipid and mononuclear cell fatty acid compositions but not mononuclear cell functions. Eur J Clin Invest 2000; 30: 260-274.

46. Calder PC. N-3 Polyunsaturated fatty acids, inflammation, and inflammatory diseases. Am J Clin Nutr 2006, 83(suppl): 1505S-19S.

47. Goldberg RJ \& Katz J. A meta-analysis of the analgesic effects of omega-3 polyunsaturated fatty acid supplementation for inflammatory joint pain. Pain $2007 ; \mathbf{1 2 9}$ : 210-223.

48. Leventhal LJ, Boyce EG \& Zurier RB. Treatment of rheumatoid arthritis with gammalinolenic acid. Ann Int Med 1993; 119: 867-873.

49. Watson L, Byars ML, McGill P et al. Cytokine and prostaglandin production by monocytes of volunteers and rheumatoid arthritis patients treated with dietary supplements of blackcurrant seed oils. Br J Rheumatol 1993; 32:1055-1058.

50. Little C. \& Parsons T. Herbal therapy for treating rheumatoid arthritis. Cochrane Database Syst Rev. 2001; 1: p. CD002948.

51. Zurier RB, Rossetti RG, Jacobsen EW et al. Gamma-linolenic acid treatment of rheumatoid arthritis. A randomized, placebo-controlled trial. Arthritis Rheum 1996; 39: 1808-1817.

52. Nordstrom DCE, Honkanen VEA, Nasu Y et al. Alpha-linolenic acid in the treatment of rheumatoid arthritis: a double-blind, placebo-controlled and randomized study: flaxseed vs safflower seed. Rheumatol Int 1995; 14: 231-234.

53. Ariza-Ariza R, Mestanza-Peralta M \& Cardiel MH. Omega-3 fatty acids in rheumatoid arthritis: an overview. Seminars in Arthritis Rheum 1998: 27: 366-370.

54. Darlington LG \& Stone TW. Antioxidants and fatty acids in the amelioration of rheumatoid arthritis and related disorders. Br J Nutr 2001; 85: 251-269.

55. Kremer JM. n-3 fatty acid supplements in rheumatoid arthritis. Am J Clin Nutr 2000; 71: 349S-351S.

56. Fortin PR, Lew RA, Liang MH et al. Validation of a Meta-Analysis: The Effects of Fish Oil in Rheumatoid Arthritis. J Clin Epidemiol 1995; 48: 1379-1390.

57. Volker D, Fitzgerald P, Major G et al. Efficacy of fish oil concentrate in the treatment of rheumatoid arthritis. J Rheumatol 2000; 27: 2343-2346.

58. Adam O, Beringer $\mathrm{C}$, Kless $\mathrm{T}$ et al. Anti-inflammatory effects of a low arachidonic acid diet and fish oil in patients with rheumatoid arthritis. Rheumatol Int 2003; 23: 27-36. 
59. Sundrarjun T, Komindr S, Archararit $\mathrm{N}$ et al. Effects of $\mathrm{n}-3$ fatty acids on serum interleukin-6, tumour necrosis factor-alpha and soluble tumour necrosis factor receptor p55 in active rheumatoid arthritis. J Int Med Res 2004; 32: 443-454.

60. Mead A, Atkinson D, Albin D et al on behalf of the UK Heart Health and Thoracic Dietitians Interest Group. Dietetic guidelines on food and nutrition in the secondary prevention of cardiovascular disease - evidence from systematic reviews of randomized controlled trials (second update, January 2006). J Hum Nutr Dietet 2006; 19: 401-419.

61. Cleland LG \& James MJ. Fish oil and rheumatoid arthritis: antiinflammatory and collateral health benefits. J Rheumatology 2000; 27: 2305-2307.

62. British Nutrition Foundation. Briefing Paper: N-3 fatty acids and health. London: British Nutrition Foundation, 1999.

63. Food Standards Agency. Survey of Dioxins and Dioxin-like PCBs in Fish Oil Supplements (Number 26/02). London: Food Standards Agency, 2002.

64. Kris-Etherton PM, Taylor DS, Yu-Poth S et al. Polyunsaturated fatty acids in the food chain in the United States. Am J Clin Nutr 2000; 71: 179-188.

65. UK Expert Group on Vitamins and Minerals. Safe Upper Levels for Vitamins and Minerals. London: Food Standards Agency, 2003.

66. Beauchamp GK, Keast RS, Morel D et al. Phytochemistry: ibuprofen-like activity in extra-virgin olive oil. Nature 2005; 437: 45-46.

67. Pattison DJ, Lunt M, Welch A et al. Diet and Disability in Early Inflammatory Polyarthritis. Rheumatology 2007; 46(suppl 1): i122.

68. McAlindon TE, Felson DT, Zhang Y et al. Do antioxidant micronutrients protect against the development and progression of knee osteoarthritis? Arthritis Rheum 1996; 39: 648-656.

69. Canter PH, Wider B \& Ernst E. The antioxidant vitamins A, C, E and selenium in the treatment of arthritis: a systematic review of randomized clinical trials. Rheumatology (Oxford) 2007; 46: 1223-33.

70. Scherak O \& Kolarz MD. Vitamin E and rheumatoid arthritis. Arthritis Rheum 1991; 34: 1205-1206.

71. Edmonds SE, Winyard PG, Guo R et al. Durative analgesic activity of repeated oral doses of vitamin $\mathrm{E}$ in the treatment of rheumatoid arthritis. Results of a prospective placebo-controlled double-blind trial. Ann Rheum Dis 1997; 56: 649-655.

72. Wittenborg A, Petersen G, Lorkowski G \& Brabant T. Effectiveness of vitamin E in comparison with diclofenac sodium in treatment of patients with chronic polyarthritis [Article in German] Zeitschrift für Rheumatologie 1998; 57: 215-221.

73. Food Standards Agency. McCance \& Widdowson's The Composition of Foods. $6^{\text {th }}$ Summary edition. Cambridge: Royal Society of Chemistry, 2002.

74. Brigelius-Flohé R, Banning A \& Schnurr K. Selenium-dependent enzymes in endothelial function. Antioxid Redox Signal 2003; 5: 205-215.

75. Vunta H, Davis F, Palempalli UD et al. The Anti-inflammatory Effects of Selenium Are Mediated through 15-Deoxy- $\{$ Delta $\}$ 12,14-prostaglandin J2 in Macrophages. J Biol Chem 2007; 282: 17964-17973.

76. Arteel GE, Briviba K \& Sies H. Protection against peroxynitrite. FEBS Letters 1999; 445: 226-230.

77. Yoon SO, Kim MM \& Chung AS. Inhibitory effect of selenite on invasion of HT1080 tumor cells. J Biol Chem 2001; 276: 20085-20092.

78. Jiang C, Jiang W, Ip C et al. Selenium-induced inhibition of angiogenesis in mammary cancer at chemopreventive levels of intake. Mol Carcinog 1999; 26: 213-25.

79. Jordan J, Fang F, Arab L et al. Low selenium levels are associated with increased risk for osteoarthritis of the knee. Abstract no. 1189, American College of 
Rheumatology/Association of Rheumatology Health Professionals Annual Scientific Meeting, 2005; November 12-17, San Diego, California.

80. Peretz A, Neve J, Duchateau J \& Famaey JP. Adjuvant treatment of recent onset rheumatoid arthritis by selenium supplementation: preliminary observations. $\mathrm{Br} \mathrm{J}$ Rheumatol 1992; 31: 281-286.

81. Heinle K, Adam A, Gradl M et al. Selenium concentration in erythrocytes of patients with rheumatoid arthritis. Clinical and laboratory chemistry infection markers during administration of selenium [Article in German] Med Klin (Munich) 1997; 92(Suppl 3): 29-31.

82. Aaseth J, Haugen M \& Førre Ø. Rheumatoid arthritis and metal compounds perspectives on the role of oxygen radical detoxification. Analyst 1998; 123: 3-6.

83. Rayman MP. The use of high-selenium yeast to raise selenium status: how does it measure up? Br J Nutr 2004; 92: 557-573.

84. Rayman MP. The importance of selenium to human health. Lancet 2000; 356: 233-241.

85. Fang YZ, Yang S \& Wu G. Free radicals, antioxidants, and nutrition. Nutrition 2002; 18: 872-879.

86. Johnson AR, Pavlovsky AG, Ortwine DF et al. Discovery and characterization of a novel inhibitor of matrix metalloprotease-13 that reduces cartilage damage in vivo without joint fibroplasia side effects. J Biol Chem 2007; 282: 27781-27791.

87. O'Dell B. Roles for iron and copper in connective tissue biosynthesis. Philos Trans R Soc Lond B Biol Sci 1981; 294: 91-104.

88. Brewer GJ. Anti-copper therapy against cancer and diseases of inflammation and fibrosis. Drug Discov Today 2005; 10: 1103-1109.

89. Omoto A, Kawahito Y, Prudovsky I et al. Copper chelation with tetrathiomolybdate suppresses adjuvant-induced arthritis and inflammation-associated cachexia in rats. Arthritis Res Ther 2005; 7: R1174-R1182.

90. Stone J, Doube A, Dudson D \&Wallace J. Inadequate calcium, folic acid, vitamin E, zinc, and selenium intake in rheumatoid arthritis patients: results of a dietary survey. Semin Arthritis Rheum 1997; 27: 180-185.

91. Peretz A, Neve J, Jeghers O \& Pelen F. Zinc distribution in blood components, inflammatory status and clinical indexes of disease activity during zinc supplementation in inflammatory rheumatic diseases. Am J Clin Nutr 1993; 57: 690-694.

92. Naveh Y, Schapira D, Ravel Y et al. Zinc metabolism in rheumatoid arthritis: plasma and urinary zinc and relationship to disease activity. J Rheumatol 1997; 24: 643-646.

93. Shenkin A. Trace elements and inflammatory response: implications for nutritional support. Nutrition 1995; 11(Suppl 1): 100-105.

94. DiSilvestro RA, Marten J \& Skehan M. Effects of copper supplementation on ceruloplasmin and copper-zinc superoxide dismutase in free-living rheumatoid arthritis patients. J Am Coll Nutr 1992; 11: 177-180.

95. Bae S-C, Kim S-J \& Sung M-K. Inadequate antioxidant nutrient intake and altered plasma antioxidant status of rheumatoid arthritis patients. J Am Coll Nutr 2003; 22: 311-315.

96. Simkin PA. Zinc sulphate in rheumatoid arthritis. Prog Clin Biol Res 1977; 14: 343-56.

97. Bates CJ, Prentice A, Cole TJ et al. Micronutrients: highlights and research challenges from the 1994-5 National Diet and Nutrition Survey of people aged 65 years and over. Br J Nutr 1999; 82: 7-15.

98. Henderson L, Irving K, Gregory J et al. Food Standards Agency. The National Diet \& Nutrition Survey: adults aged 19 to 64 years. www.statistics.gov.uk/downloads/theme health/NDNS 2003

99. Berger A. What does zinc do? Br Med J 2002; 325: 1062-1063. 
100. Blake DR, Merry P, Stevens C et al. Iron free radicals and arthritis. Proc Nutr Soc 1990; 49: 239-245.

101. Wilson A, Yu HT, Goodnough LT \& Nissenson AR. Prevalence and outcomes of anaemia in rheumatoid arthritis: a systematic review of the literature. Am J Med 2004; 116(suppl 7A): 50S-57S.

102. Punnonen K, Kaipiainen-Seppanen O, Riittinen L et al. Evaluation of iron status in anemic patients with rheumatoid arthritis using an automated immunoturbidimetric assay for transferrin receptor. Clin Chem Lab Med 2000; 38: 1297-300.

103. Fitzsimons EJ \& Sturrock RD. The chronic anaemia of rheumatoid arthritis: iron banking or blocking? Lancet 2002; 360: 1713-1714.

104. Zittermann A. Vitamin D in preventative medicine: are we ignoring the evidence? $\mathrm{Br} \mathrm{J}$ Nutr 2003; 89: 552-572.

105. Scharla SH, Schacht E \& Lempert UG. Alfacalcidol versus plain vitamin D in inflammation induced bone loss. J Rheumatol 2005; 76(suppl): 26-32.

106. Maalej A, Petit-Teixeira E, Michou L et al. Association study of VDR gene with rheumatoid arthritis in the French population. Genes Immun 2005; 6: 707-711.

107. Garcia-Lozano JR, Gonzalez-Escribano MF, Valenzuela A et al. Association of vitamin D receptor genotypes with early onset rheumatoid arthritis. Eur J Immunogenet 2001; 28: 89-93.

108. Gomez-Vaquero C, Fiter J, Enjuanes A et al. Influence of the BsmI Polymorphism of the Vitamin D Receptor Gene on Rheumatoid Arthritis Clinical Activity. J Rheumatol 2007; 34: 1823-1826.

109. Gough A, Sambrook P, Devlin J et al. Effect of vitamin D receptor gene alleles on bone loss in early rheumatoid arthritis. J Rheumatol. 1998; 25: 864-868.

110. Keen RW, Hart DJ, Lanchbury JS \& Spector TD. Association of early osteoarthritis of the knee with a Taq I polymorphism of the vitamin D receptor gene. Arthritis Rheum 1997; 40: 1444-1449.

111. Uitterlinden AG, Burger H, van Duijn CM et al. Adjacent genes, for COL2A1 and the vitamin $\mathrm{D}$ receptor, are associated with separate features of radiographic osteoarthritis of the knee. Arthritis Rheum 2000; 43: 1456-1464.

112. Cantorna MT \& Mahon BD. Mounting evidence for vitamin D as an environmental factor affecting autoimmune disease prevalence. Exp Biol Med (Maywood) 2004; 229: 1136-1142.

113. Merlino LA, Curtis J, Mikulus TR et al. Vitamin D intake is inversely associated with rheumatoid arthritis: results from the Iowa Women's Health Study. Arthritis Rheum 2004; 50: 72-77.

114. Oelzner P, Müller A, Deschner F et al. Relationship between disease activity and serum levels of vitamin D metabolites and PTH in rheumatoid arthritis. Calcif Tissue Int 1998; 62: 193-198.

115. Patel S, Farragher T, Berry J et al. Association between serum vitamin D metabolite levels and disease activity in patients with early inflammatory polyarthritis. Arthritis Rheum 2007; 56: 2143-2149.

116. DeLuca HF \& Cantorna MT. Vitamin D: its role and uses in immunology. FASEB J 2001; 15: 2579-2585.

117. Brohult J \& Jonson B. Effects of large doses of calciferol on patients with rheumatoid arthritis. A double-blind clinical trial. Scand J Rheumatol 1973; 2: 173-176.

118. Dottori L, D'Ottavio D \& Brundisini B. Calcifediol and calcitonin in the therapy of rheumatoid arthritis. A short-term controlled study. Minerva Med 1982; 73: 3033-3040. 
119. Andjelkovic Z, Vojinovic J, Pejnovic $\mathrm{N}$ et al. Disease modifying and immunomodulatory effects of high dose 1 alpha $(\mathrm{OH})$ D3 in rheumatoid arthritis patients. Clin Exp Rheumatol 1999; 17: 453-456.

120. Hypponen E \& Power C. Hypovitaminosis D in British adults at age $45 \mathrm{y}$ : nationwide cohort study of dietary and lifestyle predictors. Am J Clin Nutr 2007; 85: 860-868.

121. Holick MF. Vitamin D deficiency. N Engl J Med 2007; 357: 266-281.

122. McAlindon T \& Felson DT. Nutrition: risk factors for osteoarthritis. Ann Rheum Dis 1997; 56: 397-402.

123. McAlindon TE, Felson DT, Zhang Y et al. Relation of dietary intake and serum levels of vitamin D to progression of osteoarthritis of the knee among participants in the Framingham Study. Ann Intern Med 1996; 125: 353-359.

124. Lane NE, Gore LR, Cummings SR et al. Serum vitamin D levels and incident changes of radiographic hip osteoarthritis: a longitudinal study. Study of Osteoporotic Fractures Research Group. Arthritis Rheum 1999; 42: 854-860.

125. Felson DT, Niu J, Clancy M et al. Low levels of vitamin D and worsening of knee osteoarthritis: results of two longitudinal studies. Arthritis Rheum 2007; 56: 129-136.

126. Cantorna MT \& Mahon BD. D-hormone and the immune system. J Rheumatol 2005; 76(Suppl): 11-20.

127. Bischoff-Ferrari HA, Zhang Y, Kiel DP \& Felson DT. Positive association between serum 25-hydroxyvitamin D level and bone density in osteoarthritis. Arthritis Rheum 2005; 53: 821-826.

128. Armas LA, Hollis BW \& Heaney RP. Vitamin D2 is much less effective than vitamin $\mathrm{D}_{3}$ in humans. J Clin Endocrinol Metab 2004; 89: 5387-5391. 
Table 1: Foods found most likely to cause intolerance reported by Darlington and Ramsey [5]. NB: Dietary intolerances vary markedly from one individual to another and must be determined individually for each patient by an elimination diet followed by a reintroduction phase under the guidance of a health professional (reproduced with permission from Oxford University Press).

\begin{tabular}{lclc}
\hline Food & $\begin{array}{l}\text { Symptomatic patients } \\
\text { affected by food (\%) }\end{array}$ & Food & $\begin{array}{l}\text { Symptomatic patients } \\
\text { affected by food (\%) }\end{array}$ \\
\hline Corn & 57 & Malt & 27 \\
Wheat & 54 & Cheese & 24 \\
Bacon/pork & 39 & Grapefruit & 24 \\
Oranges & 39 & Tomato & 22 \\
Milk & 37 & Peanuts & 20 \\
Oats & 37 & Sugar (cane) & 20 \\
Rye & 34 & Butter & 17 \\
Eggs & 32 & Lamb & 17 \\
Beef & 32 & Lemons & 17 \\
Coffee & 32 & Soya & 17 \\
\hline
\end{tabular}


Table 2: Rich food sources of specific nutrients of relevance to RA/OA (data from [73])

\begin{tabular}{|c|c|c|c|c|c|c|}
\hline Vitamin C & Vitamin E & Carotenoids & Selenium & Copper & Zinc & Vitamin D \\
\hline $\begin{array}{l}\text { Blackcurrants, } \\
\text { kiwi fruit, } \\
\text { strawberries }\end{array}$ & $\begin{array}{l}\text { Vegetable } \\
\text { oils }\end{array}$ & $\begin{array}{l}\text { Carrots, } \\
\text { mange tout } \\
\text { peas, curly } \\
\text { kale, sweet } \\
\text { potato }\end{array}$ & $\begin{array}{l}\text { Brazil } \\
\text { nuts }\end{array}$ & $\begin{array}{l}\text { Crab, } \\
\text { prawns, } \\
\text { lobster, } \\
\text { mussels }\end{array}$ & $\begin{array}{l}\text { Red } \\
\text { meat }\end{array}$ & $\begin{array}{l}\text { Oily fish esp. } \\
\text { mackerel, } \\
\text { kippers, herring, } \\
\text { pilchards, trout } \\
\text { salmon, sardines }\end{array}$ \\
\hline Citrus fruits & Margarine & $\begin{array}{l}\text { Red/green } \\
\text { capsicums. }\end{array}$ & Kidney & Liver & Liver & Dairy products \\
\hline Fruit juice & $\begin{array}{l}\text { Wholegrain } \\
\text { cereals }\end{array}$ & $\begin{array}{l}\text { Tomato } \\
\text { products }\end{array}$ & Liver & Kidney & Kidney & Eggs \\
\hline $\begin{array}{l}\text { Vegetables esp. } \\
\text { curly kale, spring } \\
\text { greens, Brussels } \\
\text { sprouts, green } \\
\text { and red } \\
\text { peppers/capsicum }\end{array}$ & $\begin{array}{l}\text { Nuts and } \\
\text { seeds }\end{array}$ & $\begin{array}{l}\text { Melon } \\
\text { (orange), } \\
\text { apricots, } \\
\text { pumpkin }\end{array}$ & Fish & $\begin{array}{l}\text { Plain } \\
\text { chocolate }\end{array}$ & $\begin{array}{l}\text { Fish and } \\
\text { shellfish }\end{array}$ & $\begin{array}{l}\text { Margarine and } \\
\text { butter }\end{array}$ \\
\hline $\begin{array}{l}\text { Potatoes, sweet } \\
\text { potato }\end{array}$ & Fried foods & $\begin{array}{l}\text { Mango, } \\
\text { guava, } \\
\text { passion fruit }\end{array}$ & Shellfish & $\begin{array}{l}\text { Beans } \\
\text { and } \\
\text { lentils }\end{array}$ & $\begin{array}{l}\text { Milk } \\
\text { and } \\
\text { milk } \\
\text { products }\end{array}$ & Meat \\
\hline Potato chips & $\begin{array}{l}\text { Meat, fish, } \\
\text { eggs }\end{array}$ & $\begin{array}{l}\text { Oranges, } \\
\text { tangerines }\end{array}$ & $\begin{array}{l}\text { Lentils } \\
\text { and } \\
\text { pulses }\end{array}$ & $\begin{array}{l}\text { Brazil } \\
\text { nuts }\end{array}$ & Pulses & Cereal products \\
\hline
\end{tabular}

\section{Figure legends}

Figure 1: Desaturation and chain elongation of essential fatty acids

Figure 2: Vitamin D metabolism (adapted from [104]) 